\title{
Rheological Properties of Cement Pastes with Multiwalled Carbon Nanotubes
}

\author{
Gintautas Skripkiunas, ${ }^{1}$ Ekaterina Karpova ${ }^{D},{ }^{1}$ Irmantas Barauskas, ${ }^{2}$ \\ Joana Bendoraitiene, ${ }^{3}$ and Grigory Yakovlev ${ }^{4}$ \\ ${ }^{1}$ Department of Building Materials and Fire Safety, Vilnius Gediminas Technical University, Vilnius LT-10223, Lithuania \\ ${ }^{2}$ Department of Silicate Technology, Kaunas University of Technology, Kaunas LT-44249, Lithuania \\ ${ }^{3}$ Department of Polymer Chemistry and Technology, Kaunas University of Technology, Kaunas LT-44249, Lithuania \\ ${ }^{4}$ Department of Geo-Engineering and Construction Materials, Kalashnikov Izhevsk State Technical University, \\ Izhevsk 426069, Russia \\ Correspondence should be addressed to Ekaterina Karpova; ekaterina.karpova@vgtu.lt
}

Received 29 May 2018; Revised 4 September 2018; Accepted 9 September 2018; Published 11 October 2018

Academic Editor: Pramod Koshy

Copyright @ 2018 Gintautas Skripkiunas et al. This is an open access article distributed under the Creative Commons Attribution License, which permits unrestricted use, distribution, and reproduction in any medium, provided the original work is properly cited.

\begin{abstract}
The evaluation of rheological properties of cement systems is getting more relevant with growing interest to self-consolidating concrete (SCC), high-performance concrete (HPC) and ultrahigh-performance concrete (UHPC). The rheology models are a perspective tool to predict and manage the properties of cement systems in the fresh and hardened state. The current research is focused on the rheological test of cement systems modified by multiwalled carbon nanotubes (MWCNT) dispersion with and without polycarboxylate ether (PCE). The content of dispersion with $1 \%$ concentration of MWCNT in cement pastes varied from 0.125 to $0.5 \%$ by weight of cement. The dosage of PCE was taken as $0.6 \%$ by weight of cement. The cement pastes were prepared based on Portland cement without mineral additives. The rheological test was carried out at 5, 30, 60, and 120 min after mixing of cement paste. The rheological test established that modification of cement pastes by MWCNT dispersion in dosage $0.25 \%$ leads to the decrease of yield stress by $30.7 \%$ and increase of plastic viscosity by $29.6 \%$. The combined modification by PCE and MWCNT dispersion shows the decrease in plastic viscosity of cement pastes by $9.90 \%$ in dosage of MWCNT equal to $0.5 \%$ by weight of cement, reduction of water demand by $20 \%$ for the same workability, and decrease of yield stress till $0 \mathrm{~Pa}$. It gives the ability to obtain the self-compacting mixtures. The cement pastes with and without MWCNT dispersion revealed the shear-thinning behavior during 120 min after mixing. The modification of cement pastes by PCE with and without MWCNT dispersion showed the shear-thickening behavior which remains during $120 \mathrm{~min}$ after mixing.
\end{abstract}

\section{Introduction}

The application of rheology models based on the main rheological parameters such as viscosity, shear stress, and thixotropy can provide the ability to predict the properties of designed concrete with relatively high accuracy. This theme is becoming more relevant with growing interest to development of self-consolidating concrete (SCC), highperformance concrete (HPC) and ultrahigh-performance concrete (UHPC), and new technologies of concrete works and new fields of concrete application [1-3]. Some researchers make attempts to deduce the correlation between fundamental rheological parameters and workability of fresh concrete such as evaluation of flowability, spreadability, pumpability, slump flow, and some others which are determined via standard methods $[4,5]$.

The dilatancy observed in concrete mixtures is an important phenomenon in their transportation by pumping. The researchers investigate the dilatant behavior of concrete mixtures and explain its appearance due to the increase of system's volume under shear stress during the flow [6].

It should be noted that rheological parameters are usually determined for cement mortars and pastes. Concrete is a multicomponent material; therefore, the evaluation of 
rheological properties of concrete requires the corresponding correlation with cement pastes. The study in reference [7] provides the good correlation between mortar and fresh selfcompacting concrete as a function of the time and temperature based on the assumption that mortar and concrete are described as Bingham fluids. The properties of fine [8] and coarse aggregates [9] must be taken into account with the purpose of the prediction of rheological properties of concrete mixtures.

The rheology gives the ability to predict and manage by the properties of fresh concrete and mortar, effect on hydration kinetic, performance, and durability of cement composites [10-12]. For example, Kwasny et al. established that the increase in the yield stress value leads to the increase in the total content of the surface air voids in surface finish of cement-based mortars [12].

A number of factors influence on rheological parameters of concrete such as chemical composition and fineness of cement, particle size distribution, and geometrical parameters of solid components [13-15]; properties of filler [16, 17]; water to cement ratio [18], cement hydration, temperature and humidity $[19,20]$; parameters of mixing, used equipment for measurements of rheological properties [21, 22]; The rheological parameters of concrete depend on chemical composition and fineness of cement, particle size distribution and geometrical parameters of solid componenets [13-15], properties of filler $[16,17]$, water to cement ratio [18], cement hydration, temperature and humidity $[19,20]$, parameters of mixing and used equipment for rheological test [21, 22], properties of mineral and chemical admixtures [23-26].

The influence of mineral and chemical admixtures on the rheology of fresh concrete and mortars enables to clarify the mechanisms of their actions and make the conclusions about their effectiveness in cement systems. The insight of action mechanism of admixtures is necessary for development of new generation concrete.

Among the mineral additives, the silica fume, metakaolin, granulated blast furnace slag, and fly ash are more widely used for modification of cement composites. Frequently, they are applied as substitution of Portland cement. Ghoddousi et al. studied the influence of packing density of silica fume, metakaolin, and low activity-granulated blastfurnace slag on the rheology of self-consolidating concrete. They established the optimal packing density of about 0.804 for improvement of the rheological properties [27].

Dauksys et al. [6] investigated the dilatancy of cement paste with replacement of cement mass by microsilica. The authors identified that replacement by $9 \%$ of microsilica leads to volume change of cement paste from $1.22 \%$ to $0 \%$ and the reduction of dilatancy.

Reference [28] demonstrates that metakaolin as replacement of $20 \%$ cement increased the viscosity of the mixture due to high specific surface and irregular or plate shape of metakaolin particles.

The plasticizing admixtures, as a kind of chemical admixtures, disperse the cement particles and improve the workability of concrete. The better plasticizing effect can be reached with the increase of zeta potential and decrease of surface tension and steric effect, which is determined by molecular parameters of monomers [29]. A number of research studies are devoted to the investigation of influence of plasticizing admixtures on the rheological properties of cement systems [30, 31]. M.-H. Zhang et al. compared the effect of three types of plasticizers such as lignosulphonate, polycarboxylate, and polynaphthalene, on the loss of workability of cement pastes. They identified that yield stress and effective viscosity are lower for polycarboxylate and polynaphthalene superplasticizers in comparison with lignosulphonate at $30 \mathrm{~min}$ [32]. Polycarboxylate ether plasticizers are more commonly used in connection with their action mechanism in cement systems. The decrease of yield stress in cement systems for polycarboxylate plasticizers is caused by the steric effect of action mechanism. At the same time, the increase of viscosity is caused by polymer chains of polycarboxylate plasticizer in the solution, which leads to the cluster formation [33].

Development of nanotechnology promotes the increase of interest in the modification of cement composites by different types of nanostructures. Regardless to the excellent properties of nanostructures and improvement of the performance of cement composites by nanostructures modification in low dosages, their application in construction practice is limited. The limitation of their application is explained by the coagulation processes which take part during the storage in connection with strong van der Waals forces of nanoparticles and nanostructures. The action mechanism of nanoparticles, which is not clear in general, requires further investigations. The studying of rheological behavior of cement systems modified by nanostructures can promote the understanding of this action mechanism and make the prediction about properties of cement composites in the hardened state [34-36].

The authors of research studies [37-39] identified the reduction in the workability and increase in viscosity of cement pastes due to modification by admixtures with progressively finer sizes, such as nanosilica. They emphasized the importance to establish the optimal dosage of nanoparticles and observe the possibility to compensate the negative effect on workability by application of other admixtures, such as silica fume, fly ash, or superplasticizers. The researchers [39] established that optimal dosage of nanosilica should be less than $2 \%$ to reach the good workability of fresh mortar. The research [40] presents the increase in yield stress and viscosity of cement pastes modified by graphene oxide nanosheets.

The huge interest of researchers is paid to the modification of cement composites by carbon nanotubes (CNT) of different types. In most cases, CNT are introduced in the cement systems in dispersion form. The dispersant, type of homogenizer, and its intensity are the crucial issues in preparation of CNT dispersion. Reference [41] demonstrates the reduction in fluidity of fresh mixture modified by CNT. The authors of research studies [41-43] highlight the necessity to investigate the influence of the dispersant in combination with CNT when rheological properties of cement systems are evaluated. The authors of research [44] identified the dependence between ultrasonication energy, used in the preparation of CNT dispersion, and workability of nanomodified cement paste. It should be taken in consideration that rheological properties of nanomodified 
cement systems can be changed with changes of the binder system. Reference [45] shows the increase of plastic viscosity and yield stress in the cement mortar modified by CNT and decrease of them in fly-ash-blast furnace slag-cement mortar.

The current research is devoted to the homogenization of multiwalled carbon nanotubes (MWCNT) dispersion, methods of quality evaluation of dispersion, and the investigation of the rheological properties of nanomodified cement paste with and without polycarboxylate ether.

\section{Experimental Program}

2.1. Raw Materials. The Portland cement without mineral additives CEM I 42.5 R conforming to EN 197-1 was used as a binder. The mineral and chemical composition of the cement is presented in Table 1.

The physical and mechanical properties of the cement are listed in Table 2.

The particle size distribution of cement curve, determined by CILAS 1090, is presented in Figure 1. The operating principle of CILAS 1090 is based on laser diffraction of beams. The range of measured particles is between 0.04 and $2500 \mu \mathrm{m}$. The main content of particles of cement is from 1 to $80 \mu \mathrm{m}$ in size. The fineness of cement measured by the Blaine testing methodology reaches $4000 \mathrm{~cm}^{2} / \mathrm{g}$ specific surface value and the average value of cement particles size is $14.28 \mu \mathrm{m}$.

Potable water according to EN 1008 was used for preparation of cement pastes. The polycarboxylate ether of the MPEG type (PCE), used as plasticizing admixture for concrete, with specific gravity $1.100 \mathrm{~g} / \mathrm{cm}^{3}, \mathrm{pH}$ up to 5 at $20^{\circ} \mathrm{C}$, and dry content equal to $50.5 \%$ was applied in the research.

The MWCNT dispersion was prepared from the masterbatch "Graphistrength CW 2-45" produced by the company "Arkema" (France). The masterbatch contains 45 wt.\% of MWCNT and 55 wt.\% of carboxymethylcellulose (CMC). The MWCNT was characterized by filament length equal to $0.1-10 \mu \mathrm{m}$ and diameter equal to $15-20 \mathrm{~nm}$. The concentration of "Graphistrength CW 2-45" in the dispersion was equal to $1.0 \%$.

2.2. MWCNT Dispersion and Its Characterization. The MWCNT dispersion $(D)$ was prepared in the following way. The masterbatch "Graphistrength CW 2-45" was immersed in hot water with a temperature of about $75^{\circ} \mathrm{C}$ and stirred by standard mixer agitation of about $1000 \mathrm{rpm}$ during $15 \mathrm{~min}$. Subsequently, the dispersion was subjected to ultrasonication for a duration of $6 \mathrm{~min}$. The ultrasonication was performed by using a Bandelin Sonopuls HD 3400 ultrasonic homogenizer $(400 \mathrm{~W}, 20 \mathrm{kHz})$ with probe VS $200 \mathrm{~T}$ (Ø $25 \mathrm{~mm}$, amplitude $-82 \mu \mathrm{m})$.

The prepared MWCNT dispersion was characterized by $\mathrm{pH}$, electrical conductivity tests, measurements of zeta potential and particle size analysis. Further measurements were performed for PCE solution with and without MWCNT as well. The $\mathrm{pH}$ test was performed by using the $\mathrm{pH}$-meter Mettler-Toledo EL20 with limits of error $\pm 0.01 \mathrm{pH}$. The electrode with gel electrolyte was used. Electrical
TABLe 1: Mineral and chemical composition of cement.

\begin{tabular}{lc}
\hline Component & Amount $(\%)$ \\
\hline Tricalcium silicate $\left(\mathrm{C}_{3} \mathrm{~S}\right)$ & 57.9 \\
Dicalcium silicate $\left(\mathrm{C}_{2} \mathrm{~S}\right)$ & 15.6 \\
Tricalcium aluminate $\left(\mathrm{C}_{3} \mathrm{~A}\right)$ & 7.5 \\
Tetracalcium aluminoferrite $\left(\mathrm{C}_{4} \mathrm{AF}\right)$ & 11.9 \\
$\mathrm{Al}_{2} \mathrm{O}_{3}$ & 5.23 \\
$\mathrm{Fe}_{2} \mathrm{O}_{3}$ & 3.44 \\
$\mathrm{SiO}_{2}$ & 20.63 \\
$\mathrm{CaO}$ & 63.56 \\
$\mathrm{MgO}$ & 3.13 \\
$\mathrm{SO}$ & 0.78 \\
$\mathrm{~K}_{2} \mathrm{O}$ & 1.15 \\
$\mathrm{Na}_{2} \mathrm{O}$ & 0.10 \\
$\mathrm{Cl}^{-}$ & 0.007 \\
$\mathrm{CaO}_{\text {free }}$ & 1.4 \\
\hline
\end{tabular}

TABle 2: Physical and mechanical properties of cement.

\begin{tabular}{lc}
\hline Property & Value \\
\hline 2-day compressive strength $(\mathrm{MPa})$ & $28 \pm 2$ \\
28-day compressive strength $(\mathrm{MPa})$ & $55 \pm 3$ \\
Initial setting time $(\mathrm{min})$ & 180 \\
Final setting time $(\mathrm{min})$ & 225 \\
Volume stability $(\mathrm{mm})$ & 1.0 \\
Water consumption $(\%)$ & 26.6 \\
Residue on the $90 \mu \mathrm{m}$ sieve $(\%)$ & 1.5 \\
Specific surface $\left(\mathrm{cm}^{2} / \mathrm{g}\right)$ & 4000 \\
\hline
\end{tabular}

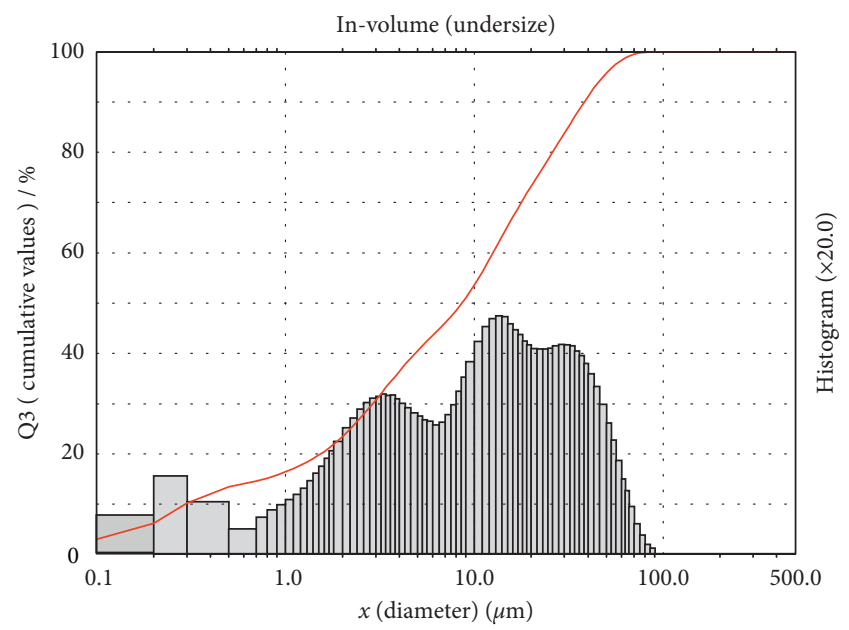

FIgURE 1: The particle size distribution of Portland cement without mineral additives.

conductivity was measured by using Mettler-Toledo EL30. The measurement range of it is 0.1 to $199.1 \mathrm{mS} / \mathrm{cm}$ with limits of error $\pm 0.5 \%$. The electrode for medium to high conductivities $(10 \mu \mathrm{S} / \mathrm{cm}, \ldots, 500 \mathrm{mS} / \mathrm{cm})$ was applied. Zeta potential measurements were performed using an electroacoustic spectrometer DT-300 (Dispersion Technology Inc.) in aqueous solution with $\mathrm{pH} 4.9-8.7$ and at a temperature of $20^{\circ} \mathrm{C}$. The particle size analysis of diluted MWCNT dispersion in the aqueous medium and polydispersity index was determined by using particle size and zeta potential analyzer DelsaNano C, Beckman Coulter. The resolution of 
measurements is placed from $0.6 \mathrm{~nm}$ to $7 \mu \mathrm{m}$. Three measurements were carried out for each sample, and average particle diameter was calculated.

2.3. Preparation of Cement Pastes and Rheology Test. The compositions of tested cement pastes are presented in Table 3.

MWCNT dispersion was dissolved in potable water. Water together with MWCNT dispersion was added to the cement, and the cement paste was mixed for $180 \mathrm{~s}$ at high speed by using a mixer. Rheological properties of cement pastes were tested in different time periods after paste mixing: 5, 30, 60, and $120 \mathrm{~min}$. The rheology tests were carried out at temperature $20 \pm 2^{\circ} \mathrm{C}$.

The rotational rheometer Rheotest RN 4.1 with coaxial cylinders was used for rheological tests. The scheme of cylinder-measuring system of the rheometer is presented in Figure 2. The assembled measuring cup (1) with coupling is poured by cement paste (3) and fixed in the equipment stand. The rotating cylinder rotor (2) is placed inside the measuring cup (1) with a gap between them of about $1.5 \mathrm{~mm}$ and rotated during the test. The intrinsic friction of cement paste layers takes place between the measuring cup (1) and cylinder rotor (2). The testing data are written when the rotating cylinder rotor makes a turn due to its connection with the measuring scale. The applied rheometer enables to test cement pastes in different modes.

The shear rate mode described by the graph in Figure 3 was used in the current experiments. Shear rate ranged from $100.0 \mathrm{~s}^{-1}$ to $0.1 \mathrm{~s}^{-1}$ during testing time. Cement pastes after mixing between tests were placed in the plastic containers and carried in the laboratory conditions with temperature $20 \pm 2{ }^{\circ} \mathrm{C}$ and relative humidity not less than $65 \%$. The cement pastes were premixed before the rheological test by hands using metallic scoop for $1 \mathrm{~min}$.

The yield stress $\left(t_{0}\right)$ and plastic viscosity $\left(\mu_{\mathrm{pl}}\right)$ were determined in the course of linear approximation of flow curves (dependence between shear stress $(\tau)$ and shear rate $(\gamma)$ in the range from 0.1 to $100 \mathrm{~s}^{-1}$ based on the Bingham model. The Bingham model is a more widely used model for description of flow behavior of cement systems, which is expressed by following equation:

$$
\tau=\tau_{0}+\mu_{\mathrm{pl}} \cdot \gamma
$$

where $\tau$, shear stress, $\mathrm{Pa} ; t_{0}$, yield stress of the cement paste, $\mathrm{Pa} ; \mu_{\mathrm{pl}}$, plastic viscosity of the cement paste, $\mathrm{Pa} \cdot \mathrm{s} ; \gamma$, shear rate, $\mathrm{s}^{-1}$.

However, in some cases, the modified form of the Bingham model or Herschel-Bulkley model is required for description of cement pastes with nonlinear character of flow. The nonlinearity of flow curves was observed for cement pastes in the course of the research. The appearance of nonlinear character of flow curves is linked with a shearthinning or shear-thickening effect which is inherent for cement pastes in some cases, especially modified by different types of chemical admixtures [46].
In the course of the current research, the attempt to evaluate the shear-thinning (shear-thickening) effect was made. The shear-thinning (shear-thickening) effects of cement pastes, as property of cement paste to decrease (increase) the plastic viscosity with increase of shear stress were determined by the usage of the traditional Bingham model in the ranges of shear rate $20-40 \mathrm{~s}^{-1}$ and $80-100 \mathrm{~s}^{-1}$. The experimental flow curves were approximated in these ranges, and values of viscosity were obtained. Equation (2) was derived to calculate the value of shear-thinning (shearthickening) effects within the specified range of shear rates as follows:

$$
T=\frac{\mu_{\mathrm{pl}, 20-40}-\mu_{\mathrm{pl}, 80-100}}{\mu_{\mathrm{pl}, 20-40}} \cdot 100 \%,
$$

where $\mu_{\mathrm{pl}, 20-40}$, plastic viscosity of cement paste in interval $20-40 \mathrm{~s}^{-1}(\mathrm{~Pa} \cdot \mathrm{s})$ and $\mu_{\mathrm{pl}, 80-100}$, plastic viscosity of cement paste in interval $80-100 \mathrm{~s}^{-1}(\mathrm{~Pa} \cdot \mathrm{s})$.

\section{Results and Discussion}

3.1. Investigation of MWCNT Dispersion Stability. The results of $\mathrm{pH}$, electrical conductivity, zeta potential measurements for PCE aqueous solution, and MWCNT aqueous dispersion and their mixtures are presented in Table 4.

Addition of PCE to MWCNT dispersion led to the decrease of the $\mathrm{pH}$ level of the system. Meanwhile, the electrical conductivity of PCE and MWCNT dispersion mixture was slightly higher compared with those separate components. These changes can be attributed to the chemical composition of PCE and physical interactions between molecules of the plasticizer and MWCNT.

More attention should be paid to zeta potential measurements of MWCNT dispersion with and without plasticizers. Zeta potential is presented on the boundary of the adsorption and diffuse layer. Determination of zeta potential is more simple and quite accurate method to predict the stability of colloidal systems. The colloidal systems are more stable with higher zeta potential.

Figure 4 shows the scheme of appearance of zeta potential on the MWCNT surface. MWCNT and agglomerates of MWCNT can have the layer of the potential-determining ions on the surface in connection with their small sizes. The potential-determining ions form the adsorption layer which has the diffusion layer around.

In the course of the current research, the zeta potentials were up to $1.79 \mathrm{mV},-14.51 \mathrm{mV},-2.72 \mathrm{mV}$, respectively, for PCE, MWCNT dispersions without, and with PCE. The higher value of zeta potential in MWCNT dispersion in comparison with PCE and mixture with PCE and MWCNT can be explained by the large-specific surface area of MWCNT particles and the great adsorption value of liquid phase molecules (Figure 4). The MWCNT dispersion with zeta potential equal to -14.51 is quite stable; however, addition of PCE leads to decrease of zeta potential and reduce the stability of MWCNT, water and PCE system. 
TABLe 3: Content of materials for $1 \mathrm{~m}^{3}$ in tested cement pastes.

\begin{tabular}{lcccccc}
\hline Specimen & Cement $(\mathrm{kg})$ & Water $(\mathrm{kg})$ & W/C ratio & PCE $(\mathrm{kg})$ & MWCNT $(\mathrm{kg})$ & MWCNT dispersion $(\mathrm{kg})$ \\
\hline D0 & 935 & 281 & 0.30 & 0 & 0 & 0 \\
D1 & 935 & 279 & 0.30 & 0 & 0.01 & 0.02 \\
D2 & 935 & 278 & 0.30 & 0 & 0.05 & 2.34 \\
D3 & 935 & 276 & 0.30 & 0 & 0 & 4.68 \\
P & 935 & 219 & 0.24 & 5.61 & 0.01 & 0 \\
PD1 & 935 & 218 & 0.24 & 5.61 & 0.02 & 1.17 \\
PD2 & 935 & 217 & 0.24 & 5.61 & 0.05 & 4.34 \\
PD3 & 935 & 214 & 0.24 & 5.61 & 0.68 \\
\hline
\end{tabular}

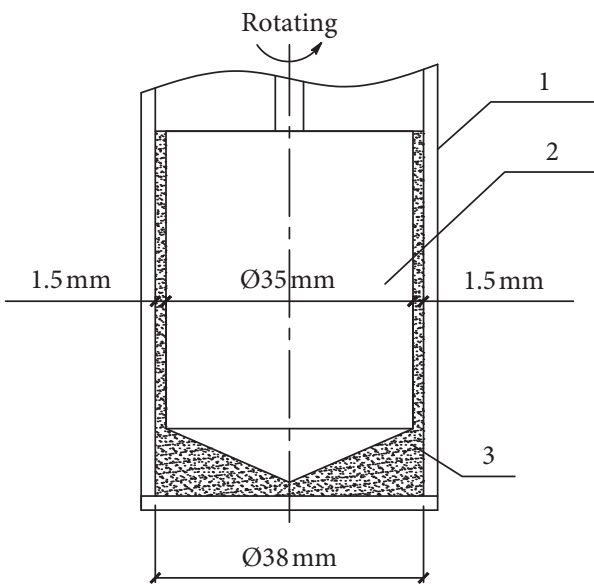

FIGURE 2: Scheme of cylinder-measuring system Rheotest RN 4.1.

In addition, the particle size analysis of dispersion is essential to make the conclusion about quality of dispersion. In the course of the current research, the particle size analysis, tested using an electroacoustic spectrometer, was performed for PCE solution, MWCNT dispersion, and their mixture. The results of particle size analysis are presented in Figure 5.

The particle size analysis of PCE solution revealed that the size of the derivatives in the sample ranged from 3 to $65 \mathrm{~nm}$ and the average diameter of polymer particles was about $31.5 \mathrm{~nm}$. The dimension of MWCNT dispersion particles varied from 119 to $1070 \mathrm{~nm}$ with the average size up to $397.4 \mathrm{~nm}$. The mixture of PCE and MWCNT dispersion was yielded as the sample with particle size distribution similar to that for MWCNT dispersion. Moreover, the typical peaks for PCE were not apparent, and little content of particles with dimensions up to $5 \mathrm{~nm}$ was obtained. The presence of modified particles in the range from 138 to $1000 \mathrm{~nm}$ with an average particle diameter up to $354.7 \mathrm{~nm}$ is caused by interactions of PCE molecules and MWCNT in mixture. The polydispersity index presents the deviation of particle size in dispersion from the average value. Addition of MWCNT dispersion to PCE reduces the polydispersity index from 0.344 to 0.197 which points out on better distribution of particles (Table 4). The zeta potential measurements and particle size analysis revealed that MWCNT dispersion without introduction of PCE possesses the better stability with zeta

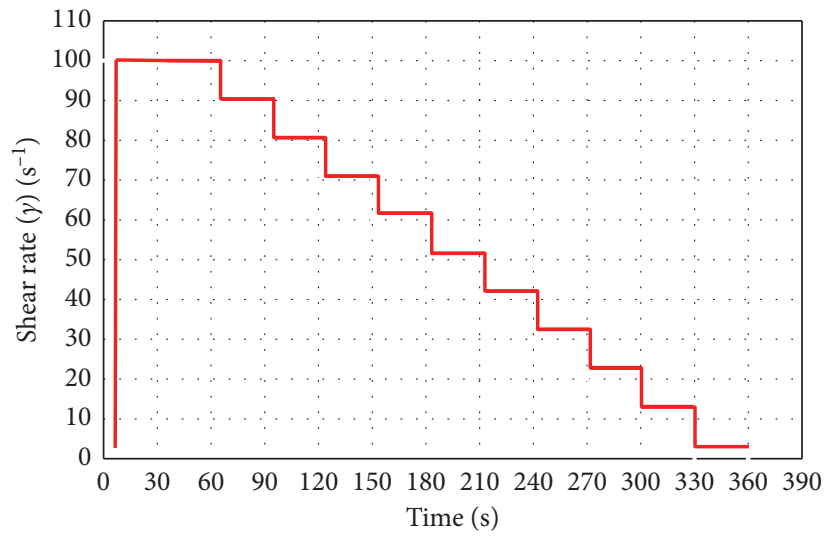

Figure 3: Shear rate mode of rheological test.

potential up to -14.51 and average particle size diameter of $397.4 \mathrm{~nm}$. The applied PCE decreases the zeta potential value up to -2.72 and decreases the stability of the system. The research on the modification of PCE can promote the achievement of a more stable system.

3.2. Flow Behavior of Nanomodified Cement Pastes with and without PCE. Figures 6 and 7 present the flow behavior of nanomodified cement pastes in different dosages of MWCNT dispersion after 5 and $120 \mathrm{~min}$ from mixing, respectively. The flow curves equations according to the Bingham model are written near the corresponding curves. The values of plastic viscosity and yield stress after 5 and 120 min of mixing based on experimental equations are presented in Table 5.

The equations of cement pastes flow behavior according to the Bingham model were derived and presented in Figure 6 together with flow curves of pastes with different dosages of MWCNT dispersion. The yield stress and plastic viscosity values for cement pastes with different dosages of MWCNT after 5 and 120 min after mixing were determined and are presented in Table 5.

The introduction of MWCNT dispersion changes the flow behavior of cement pastes. The increase of shear stress and plastic viscosity of nanomodified cement pastes is observed in Figure 6 in the range of shear rate from 0.1 to $100 \mathrm{~s}^{-1}$ in $5 \mathrm{~min}$ after mixing. The maximum increase of shear stress was identified for cement paste modified by MWCNT dispersion in dosage $0.25 \%$ by weight of cement. 
TABLE 4: Characteristics of the samples.

\begin{tabular}{lccc}
\hline Property & Polycarboxylate ether & MWCNT dispersion & Polycarboxylate ether + MWCNT dispersion \\
\hline $\mathrm{pH}$ & 5.00 & 8.67 & 4.91 \\
Electrical conductivity $(\mathrm{mS} / \mathrm{cm})$ & 3.12 & 3.32 & 3.55 \\
Average diameter $(\mathrm{nm})$ & 31.5 & 397.4 & 354.7 \\
Zeta potential $(\mathrm{mV})$ & 1.79 & -14.51 & -2.72 \\
Polydispersity index & 0.344 & 0.186 & 0.197 \\
\hline
\end{tabular}

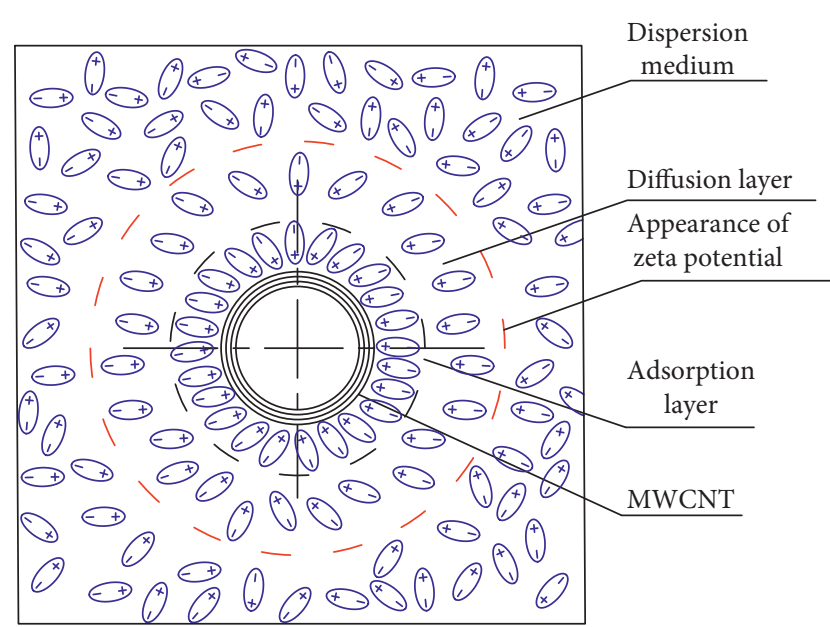

FIgURE 4: Zeta potential on the MWCNT surface.

The shear-thinning behavior takes place in the course of modification of cement paste by MWCNT dispersion. At the same time, as it is seen in Figure 7, shear stress and plastic viscosity were not changed for nanomodified cement pastes in the range of shear rate from 0.1 to $100 \mathrm{~s}^{-1}$ after $120 \mathrm{~min}$ of mixing. In other words, the plasticizing effect of MWCNT dispersion does not remain during the time due to physical-chemical processes in cement paste.

Figures 8 and 9 present the flow behavior of nanomodified cement pastes with PCE in different dosages in range from 0.125 to $0.5 \%$ by weight of cement in 5 and $120 \mathrm{~min}$ after mixing, respectively. The flow curve equations according to the Bingham model are written near the corresponding curves. The values of plastic viscosity and yield stress after 5 and 120 min of mixing based on experimental equations for cement pastes with PCE without and with MWCNT dispersion are presented in Table 6.

Plastic viscosity decreases slightly for cement pastes modified by PCE and MWCNT dispersion after 5 min of mixing in comparison with the sample modified only by PCE. The nanomodified cement pastes with PCE show the shear-thickening character of flow. As it is observed in Figure 9, the plasticizing effect remains on the same level during the $120 \mathrm{~min}$ after mixing of cement pastes.

Thus, modification of cement pastes by MWCNT dispersion demonstrates the shear-thinning behavior and the plasticizing effect after $5 \mathrm{~min}$ of mixing, which disappears after $120 \mathrm{~min}$.

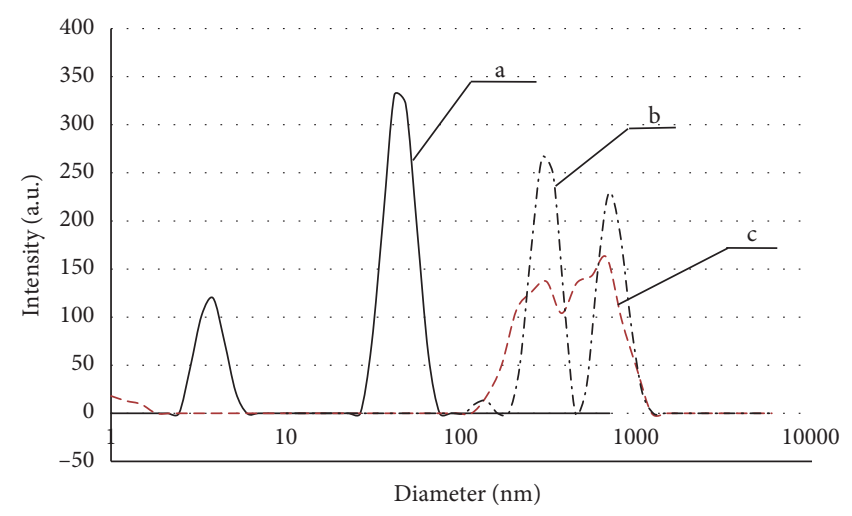

Figure 5: The particle size distribution by intensity of PCE solution (a), MWCNT dispersion (b), and PCE + MWCNT dispersion (c).

Cement pastes modified by MWCNT dispersion with PCE present the shear-thickening behavior and retain the plasticizing effect during the $120 \mathrm{~min}$.

3.3. Plastic Viscosity and Yield Stress of Nanomodified Cement Pastes with and without PCE. Based on linear approximation and processing the experimental flow curves by the Bingham model, the dimensions of yield stress and plastic viscosity were obtained. The variation of yield stress and plastic viscosity were calculated based on the data presented in Tables 5 and 6.

Figure 10 presents the variation of yield stress and plastic viscosity of nanomodified cement paste in comparison with the reference sample without MWCNT dispersion after 5 min of mixing. The yield stress of nanomodified cement pastes decreases in the range from 15 to $30 \%$ in comparison with the reference sample without admixture. The maximum decrease in yield stress by $30.7 \%$ is observed for cement paste modified by MWCNT dispersion in dosage $0.25 \%$ by weight of cement.

The plastic viscosity increases in the range from 9 to $30 \%$ for nanomodified cement pastes in comparison with the reference sample. The maximum increase of plastic viscosity by $29.59 \%$ was established for cement pastes with MWCNT dispersion in the dosage $0.25 \%$ by weight of cement.

The data about variation of yield stress and plastic viscosity of cement pastes modified by MWCNT dispersion and PCE are presented in Figure 11. The usage of PCE with and without MWCNT dispersion leads to decrease of yield stresses of modified cement pastes up to $0 \mathrm{~Pa}$.

The viscosity of nanomodified cement pastes with PCE decreases in the range from 2 to $9 \%$ in comparison with 


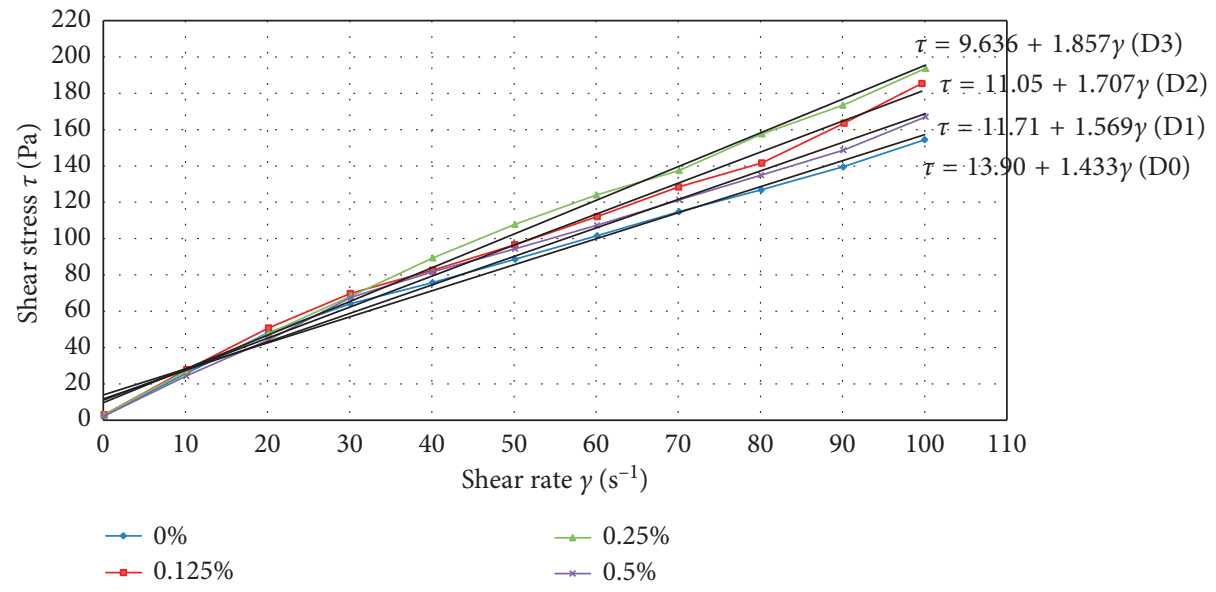

FIgURE 6: Flow curves of nanomodified cement pastes after 5 min of mixing.

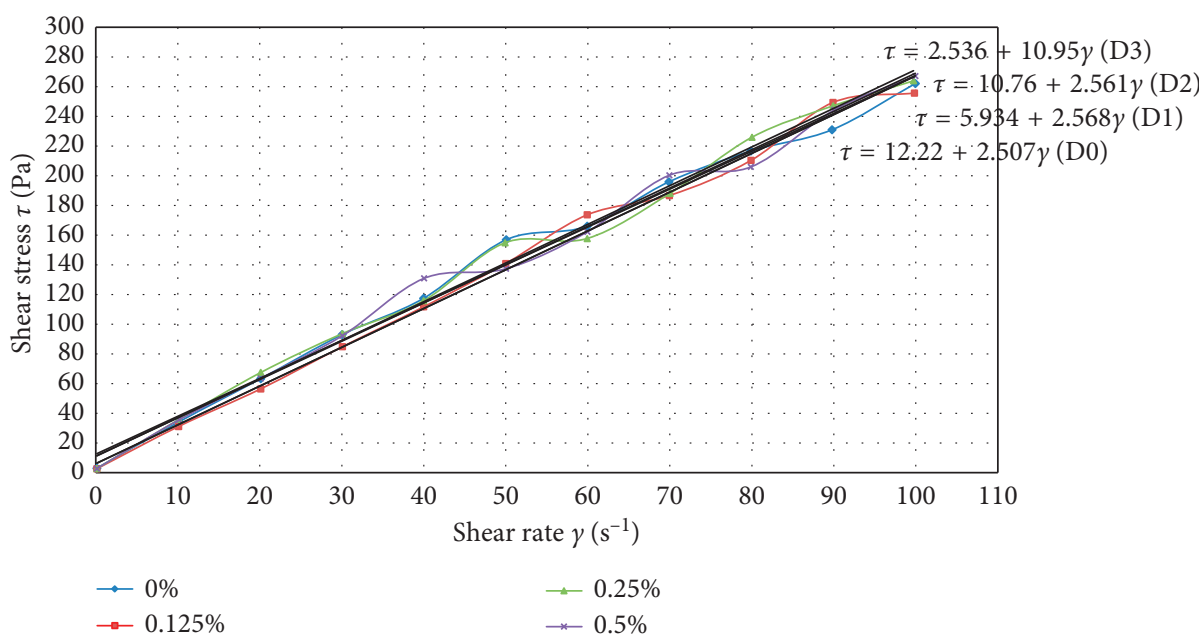

Figure 7: Flow curves of nanomodified cement pastes after $120 \mathrm{~min}$ of mixing.

TABLE 5: Values of plastic viscosity and yield stress for nanomodified cement pastes.

\begin{tabular}{lcccc}
\hline \multirow{2}{*}{ Dosage of MWCNT dispersion (\%) } & \multicolumn{2}{c}{ After 5 min } & \multicolumn{2}{c}{ After 120 min } \\
& Yield stress (Pa) & Plastic viscosity, (Pa.s) & Yield stress (Pa) & Plastic viscosity (Pa.s) \\
\hline 0 & 13.90 & 1.433 & 12.22 & 2.507 \\
0.125 & 11.71 & 1.569 & 5.934 & 2.568 \\
0.25 & 11.05 & 1.707 & 10.76 & 2.561 \\
0.5 & 9.636 & 1.857 & 10.95 & 2.536 \\
\hline
\end{tabular}

reference samples modified only by PCE. The maximum decrease of plastic viscosity by $9.90 \%$ was identified for cement paste with PCE and MWCNT dispersion in the dosage $0.5 \%$ by weight of cement.

The results presented in Figures 12 and 13 describe the changes of plastic viscosity during the testing time.

The plastic viscosity of cement pastes tested after $120 \mathrm{~min}$ increases approximately by 1.5 times for all specimens in comparison with viscosity of cement pastes tested after $5 \mathrm{~min}$.
The plastic viscosity of cement pastes modified by PCE in combination with MWCNT dispersion remains the same within 120 min duration time (Figure 13).

Thus, modification of cement pastes by MWCNT dispersion leads to increase of viscosity and decrease of yield stress for cement pastes tested after $5 \mathrm{~min}$. The increase of viscosity for cement pastes tested after $120 \mathrm{~min}$ did not observed.

The modification of cement pastes by PCE with and without MWCNT dispersion demonstrated the decrease of 


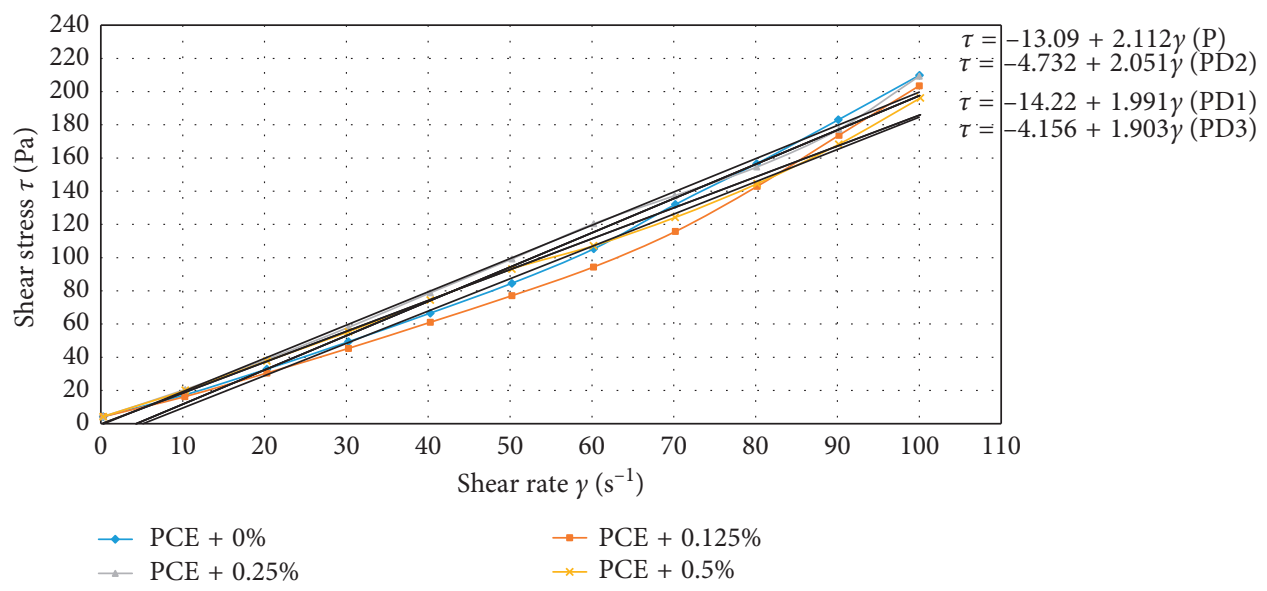

FIGURE 8: Flow curves of nanomodified cement pastes with PCE after 5 min of mixing.

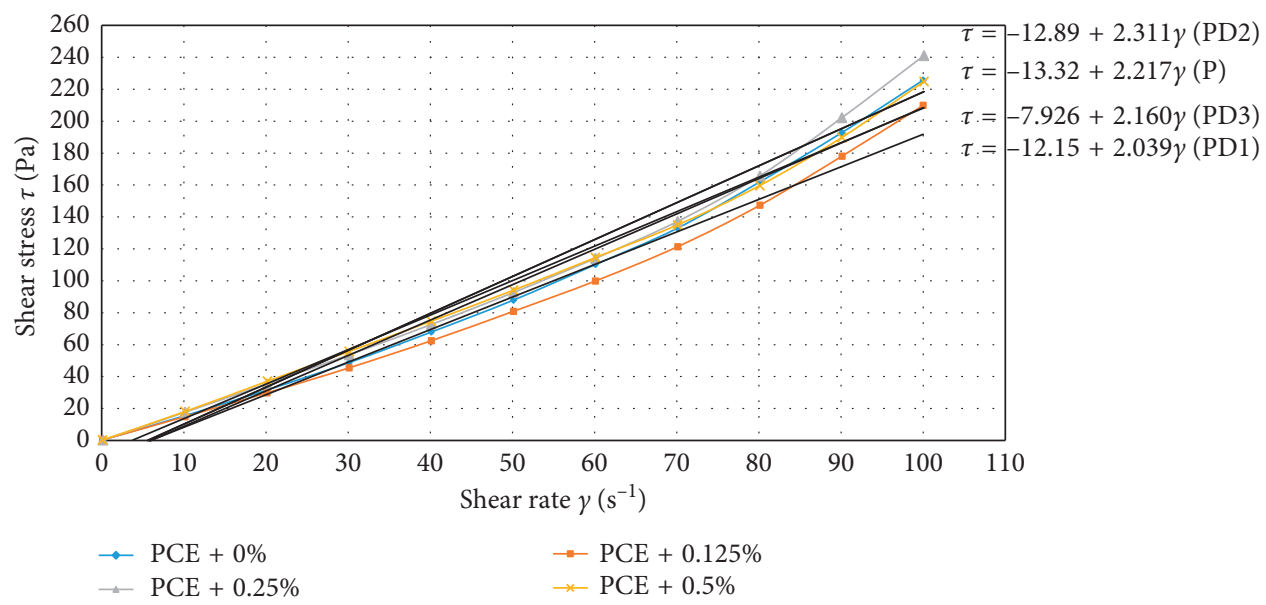

FIGURE 9: Flow curves of nanomodified cement pastes with PCE after $120 \mathrm{~min}$ of mixing.

TABLE 6: Values of plastic viscosity and yield stress for nanomodified cement pastes with PCE.

\begin{tabular}{lcccc}
\hline \multirow{2}{*}{ Dosage of PCE +MWCNT dispersion (\%) } & \multicolumn{2}{c}{ After 5 min } & \multicolumn{2}{c}{ After 120 min } \\
& Yield stress (Pa) & Plastic viscosity, (Pa.s) & Yield stress (Pa) & Plastic viscosity (Pa.s) \\
\hline PCE & 0 & 2.112 & 0 & 2.217 \\
PCE +0.125 & 0 & 1.991 & 0 & 2.039 \\
PCE +0.25 & 0 & 2.051 & 0 & 2.311 \\
PCE +0.5 & 0 & 1.903 & 0 & 2.160 \\
\hline
\end{tabular}

yield stress till $0 \mathrm{~Pa}$ and decrease of plastic viscosity. The plasticizing effect is remained during $120 \mathrm{~min}$.

3.4. Shear-Thinning and Shear-Thickening Behavior of Nanomodified Cement Pastes. The reference cement paste and cement pastes modified by different dosages of MWCNT dispersion demonstrate the shear-thinning behavior (Figure 14), which remains within 120 min duration time of mixing. The maximum appearance of shear-thinning behavior by $20.9 \%$ was established for cement paste modified with $0.25 \%$ of MWCNT dispersion by weight of cement after 120 min of mixing.

The introduction of PCE changes the shear-thinning behavior of cement pastes on shear-thickening behavior. The shear-thickening properties remains within $120 \mathrm{~min}$ duration time of mixing.

As it can be seen in Figure 15, the shear-thickening effect for PCE was $58.7 \%$ and $76.5 \%$ after 5 and 120 min of mixing, respectively. The decrease of shear-thickening effect is necessary for concrete technology. The addition of MWCNT dispersion to PCE enables to decrease shear- 


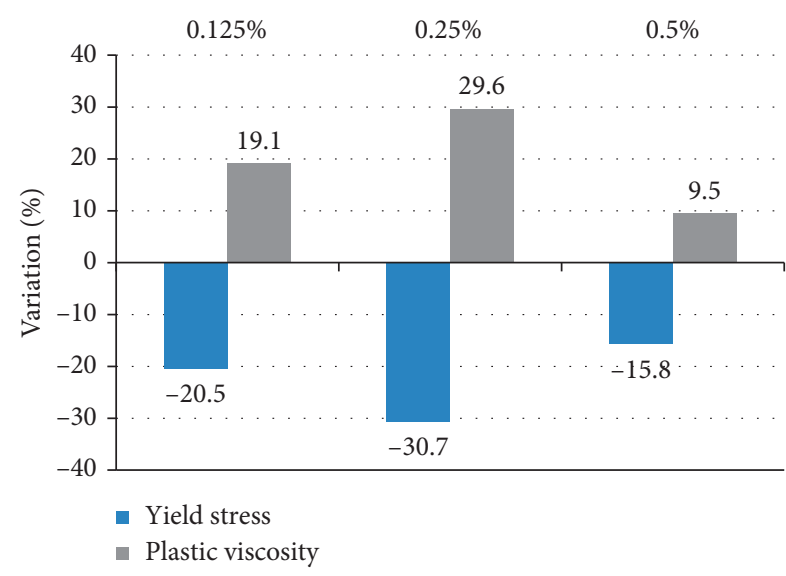

FIGURE 10: Variation of yield stress and plastic viscosity of nanomodified cement pastes.

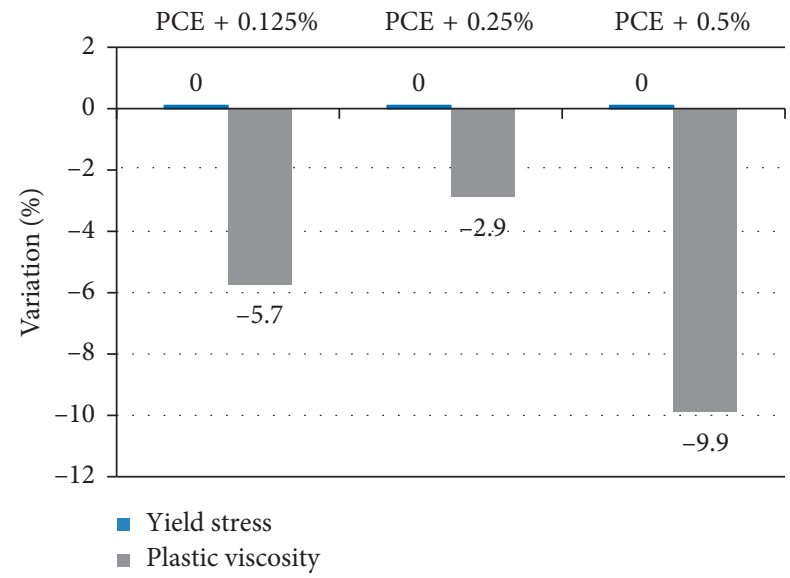

FIgURE 11: Variation of yield stress and plastic viscosity of nanomodified cement pastes with PCE.

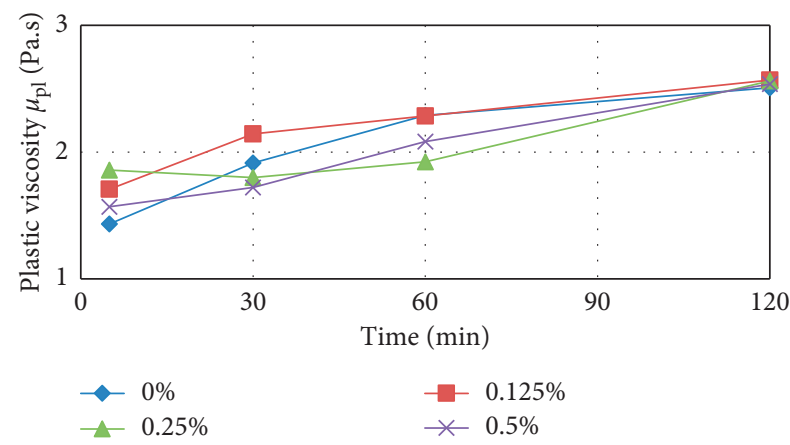

FIGURE 12: Variation of plastic viscosity of nanomodified cement pastes within $120 \mathrm{~min}$ duration.

thickening effect. The optimal results were obtained for cement paste with PCE and MWCNT dispersion in the dosage of $0.5 \%$ by weight of cement. The shear-thickening effect was decreased by $18.1 \%$ and $3.8 \%$ for 5 and $120 \mathrm{~min}$ after mixing, respectively, in comparison with cement paste with PCE.

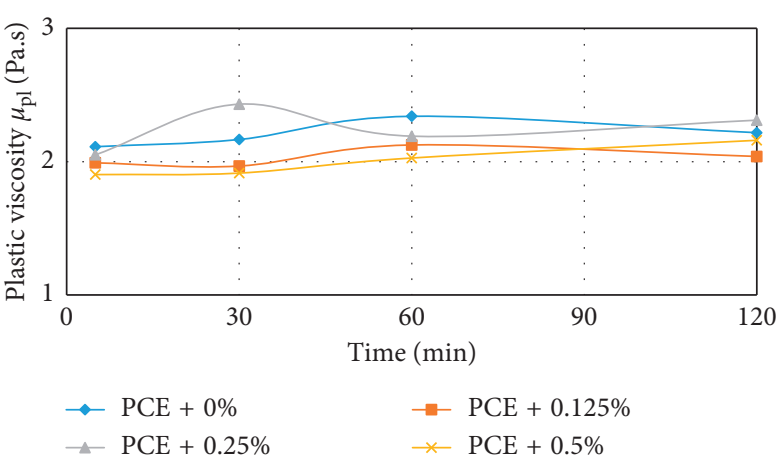

FIGURE 13: Variation of plastic viscosity of nanomodified cement pastes with PCE within 120 min duration.

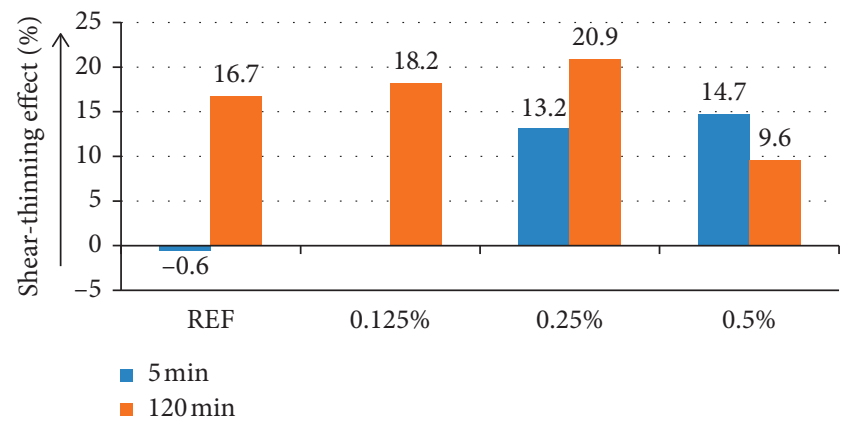

FIgURE 14: Shear-thinning behavior of nanomodified cement pastes within 5 and $120 \mathrm{~min}$ duration.

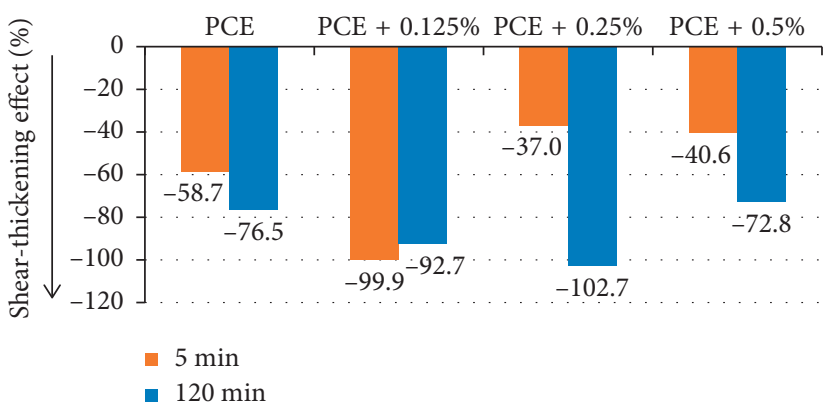

FIGURE 15: Shear-thickening behavior of nanomodified cement pastes with PCE within 5 and 120 min duration.

Thus, the cement pastes with and without MWCNT dispersion demonstrated the shear-thinning behavior; however, it was noticed that MWCNT dispersion does not influence significantly on appearance of this behavior. The shear-thinning behavior remains during $120 \mathrm{~min}$ of testing. The application of PCE leads to shear-thickening behavior of cement paste, which remains for $120 \mathrm{~min}$ after mixing. The introduction of MWCNT enables to decrease the shearthickening effect.

3.5. Mechanism of Interactions between Particles and Its Influence on Rheology of Cement Paste. The rheological parameters of cement pastes are determined by parameters of solid particles and their interactions in the mixture. The 


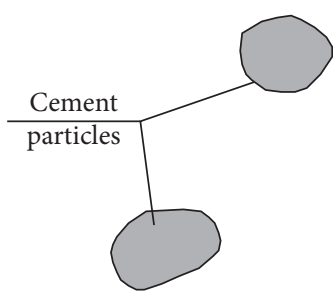

$\mathrm{W} / \mathrm{C}=0.30$

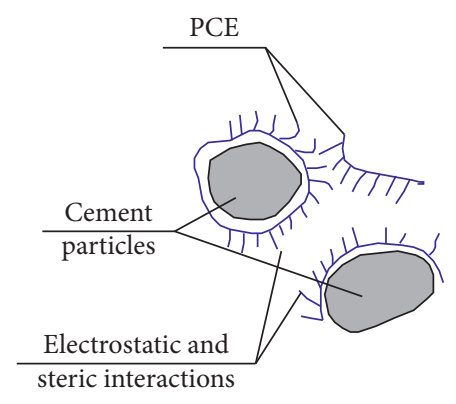

$\mathrm{W} / \mathrm{C}=0.24$

(a)

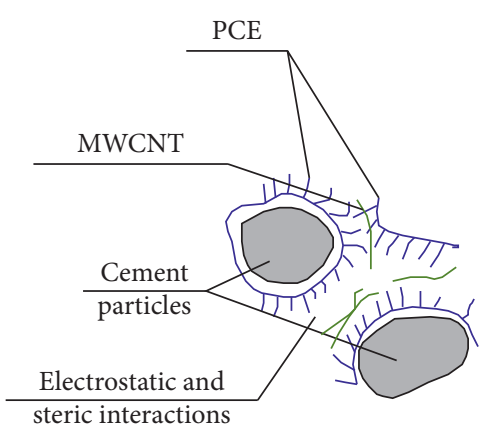

$\mathrm{W} / \mathrm{C}=0.24$

(c)

Figure 16: Mechanism of interaction of cement particles. (a) Without PCE. (b) With PCE. (c) With PCE and MWCNT dispersion.

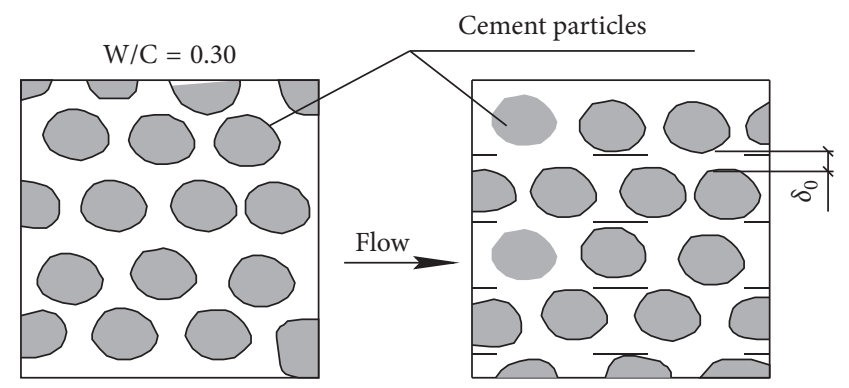

(a)

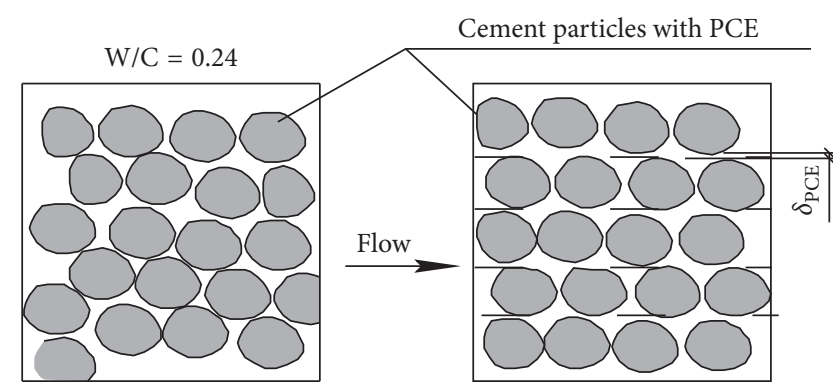

(b)

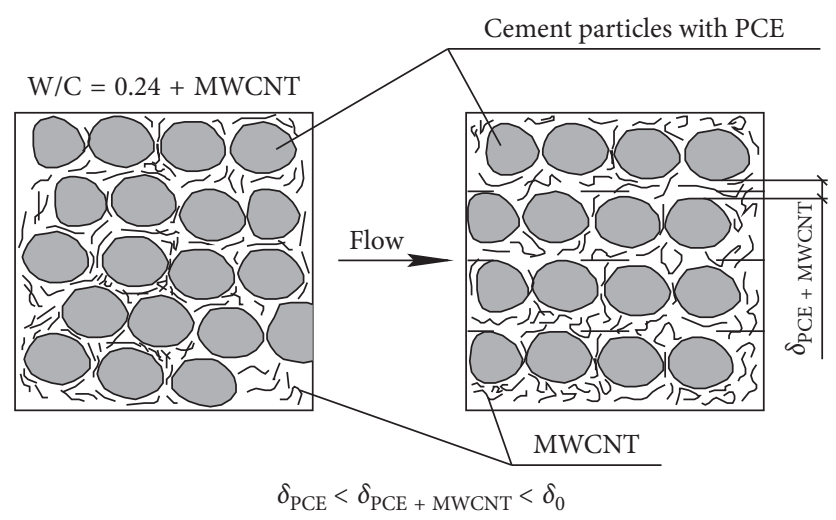

(c)

FIGURe 17: Flow behavior of cement pastes: (a) Without PCE. (b) With PCE. (c) With PCE and MWCNT dispersion.

attempts to find the dependence between rheological parameters and particle interactions were made in some rheological models. For instance, the Yodel model introduces the interparticle force parameter which depends on van der Waals attractive forces and electrostatic and steric interactions $[47,48]$.

It should be noted that interactions between cement particles are determined by water-cement ratio as well. In the course of the current research, the cement pastes with water to cement ratio equal to 0.30 were tested; the introduction of PCE in dosage $0.6 \%$ by weight of cement leaded to the decrease of water to cement ratio from 0.3 to 0.24 for the same consistency of cement paste. The reduction of the amount of water in cement pastes leads to the decrease of spaces between cement grains and increase of shearthickening effect in cement paste. The application of plasticizer allows to reach the cement pastes with equal consistence, reduce liquid phase, and reach low distance between cement particles. The mechanisms of interactions between cement particles in different conditions are presented in Figure 16.

As it is observed in Section 3.4, cement pastes can present the shear-thinning and shear-thickening behavior under mechanical action. Figure 17 shows the scheme of flow behavior of cement paste without PCE, with PCE, and with combined addition of MWCNT dispersion and PCE. 
The properties of particles and interaction forces between them play the important role in this case as well.

The modification of cement pastes by PCE leads to the decrease of yield stress and plastic viscosity which are explained by electrostatic and steric forces in cement paste.

The cement pastes with MWCNT dispersion subjected to mechanical action showed the shear-thinning effect which can be explained by changes in volume distribution of cement particles and the increase of space between them.

The introduction of MWCNT dispersion in the cement system with PCE slightly increases the plasticizing effect. This fact can be explained by the steric effect and the increase of thickness of liquid phase between layers of cement paste.

The cement pastes modified by PCE with and without MWCNT dispersion demonstrated the shear-thickening behavior, which is linked with the decrease of the thickness of the liquid phase between layers in cement paste (Figure 17(c)).

Further investigation and formation of rheological models depending on the properties of particles and their interactions are required. The application of plasticizers has a great perspective in managing the rheological properties of cement pastes with and without nanoparticles.

\section{Conclusions}

The following conclusions are drawn in this study:

(1) The MWCNT dispersion for modification of cement pastes with average particle diameter up to $397 \mathrm{~nm}$ and zeta potential up to -14.5 was obtained in the course of the research. The duration of ultrasonication about $6 \mathrm{~min}$ and the power equal to $400 \mathrm{~W}$ were established as optimal parameters of nano-dispersion homogenization.

(2) The decrease of zeta potential from -14.5 up to -2.72 and the reduction of stability were obtained with addition of PCE to MWCNT dispersion. The modification of PCE can promote the achievement of the more stable system.

(3) The modification of cement pastes by MWCNT dispersion presented the plasticizing effect for cement pastes tested in $5 \mathrm{~min}$ after mixing, which did not remain after $120 \mathrm{~min}$ of mixing. The modification of cement pastes by PCE with and without MWCNT dispersion leads to storage of plasticizing effect during $120 \mathrm{~min}$ after mixing.

(4) The modification of cement pastes by MWCNT dispersion enables the decrease of the yield stress. The maximum decrease in yield stress by $30.7 \%$ is observed for cement paste modified by MWCNT dispersion in dosage of $0.25 \%$ by weight of cement.

The complex application of PCE and MWCNT dispersion decreases the water demand by $20 \%$ and decreases yield stress till $0 \mathrm{~Pa}$.
(5) The maximum increase of plastic viscosity by $29.59 \%$ was established for cement pastes with addition of MWCNT dispersion in the dosage of $0.25 \%$ by weight of cement after $5 \mathrm{~min}$ of mixing. The difference in plastic viscosity is not significant for all cement pastes with different contents of MWCNT tested in 120 min after mixing. The plastic viscosity of nanomodified cement pastes tested after $120 \mathrm{~min}$ increases approximately by 1.5 times for all specimens in comparison with viscosity of cement pastes tested in 5 min after mixing.

(6) The cement pastes with MWCNT dispersion showed the shear-thinning behavior, which remains within 120 min duration time after mixing. The shearthinning effect by $21 \%$ was established for cement paste modified with $0.25 \%$ of MWCNT dispersion by weight of cement. MWCNT effects marginally on the shear-thinning behavior of cement pastes in comparison with cement paste without MWCNT.

(7) The addition of PCE change the shear-thinning behavior of cement pastes on shear-thickening behavior, which remains in 120 min after mixing. The addition of MWCNT dispersion to PCE enables to decrease shear-thickening effect. The optimal results were obtained for cement paste with PCE and MWCNT dispersion in the dosage of $0.5 \%$ by weight of cement. The shear-thickening effect was decreased by $18.1 \%$ and $3.8 \%$ for 5 and 120 min after mixing in comparison with cement paste without MWCNT.

\section{Data Availability}

The experimental data used to support the findings of this study are available from the corresponding author upon request.

\section{Conflicts of Interest}

The authors declare that there are no conflicts of interest regarding the publication of this paper.

\section{References}

[1] J. Dils, V. Boel, and G. De Schutter, "Influence of cement type and mixing pressure on air content, rheology and mechanical properties of UHPC," Construction and Building Materials, vol. 41, pp. 455-463, 2013.

[2] D. Feys, K. H. Khayat, and R. Khatibk, "How do concrete rheology, tribology, flow rate and pipe radius influence pumping pressure?," Cement and Concrete Composites, vol. 66, pp. 38-46, 2016.

[3] I. Gonzalez-Taboada, B. Gonzalez-Fonteboa, J. Eiras-Lopez, and G. Rojo-Lopez, "Tools for the study of self-compacting recycled concrete fresh behavior: workability and rheology," Journal of Cleaner Production, vol. 156, pp. 1-18, 2017.

[4] H. Xie, F. Liu, Y. Fan et al., "Workability and proportion design of pumping concrete based on rheological parameters," Construction and Building Materials, vol. 44, pp. 267275, 2013. 
[5] V. Mechtcherine, V. Naidu Nerella, and K. Kasten, "Testing pumpability of concrete using Sliding Pipe Rheometer," Construction and Building Materials, vol. 53, pp. 312-323, 2014.

[6] M. Dauksys and G. Skripkiunas, "Investigation of dilatancy mechanism of Portland cement paste," Construction and Building Materials, vol. 83, pp. 53-61, 2015.

[7] J. Golaszewski, A. Kostrzanowska-Siedlarz, G. Cygan, and M. Drewniok, "Mortar as a model to predict self-compacting concrete rheological properties as a function of time and temperature," Construction and Building Materials, vol. 124, pp. 1100-1108, 2016.

[8] J. Zhang, X. An, and D. Nie, "Effect of fine aggregate characteristics on the thresholds of self-compacting paste rheological properties," Construction and Building Materials, vol. 116, pp. 355-365, 2016.

[9] J. Hu and K. Wang, "Effect of coarse aggregate characteristics on concrete rheology," Construction and Building Materials, vol. 25, no. 3, pp. 1196-1204, 2011.

[10] K. Kovler and N. Roussel, "Properties of fresh and hardened concrete," Cement and Concrete Research, vol. 41, no. 7, pp. 775-792, 2011.

[11] I. Mehdipour, A. Kumar, and K. H. Khayat, "Rheology, hydration, and strength evolution of interground limestone cement containing PCE dispersant and high volume supplementary cementitious materials," Materials and Design, vol. 127, pp. 54-66, 2017.

[12] J. Kwasny, M. Sonebi, J. Plasse, and S. Amziane, "Influence of rheology on the quality of surface finish of cement-based mortars," Construction and Building Materials, vol. 89, pp. 102-109, 2015.

[13] H. Vikan, H. Justnes, F. Winnefeld, and R. Figi, "Correlating cement characteristics with rheology of paste," Cement and Concrete Research, vol. 37, no. 11, pp. 1502-1511, 2007.

[14] J. J. Chen and A. K. H. Kwan, "Superfine cement for improving packing density, rheology and strength of cement paste," Cement and Concrete Composites, vol. 34, no. 1, pp. 1-10, 2012.

[15] D. Nagrockiene, I. Pundiene, and A. Kicaite, "The effect of cement type and plasticizer addition on concrete properties," Construction and Building Materials, vol. 45, pp. 324-331, 2013.

[16] R. Talero, C. Pedrajas, M. Gonzalez, C. Aramburo, and A. Blazquez, "Role of the filler on Portland cement hydration at very early ages: rheological behavior of their fresh cement pastes," Construction and Building Materials, vol. 151, pp. 939-949, 2017.

[17] R. Cepuritis, S. Jacobsen, B. Pedersen, and E. Mørtsell, "Crushed sand in concrete e effect of particle shape in different fractions and filler properties on rheology," Cement and Concrete Composites, vol. 71, pp. 26-41, 2016.

[18] A. Yahia and M. Tanimura, "Rheology of belite-cement-effect of w/c and high-range water-reducer type," Construction and Building Materials, vol. 88, pp. 169-174, 2015.

[19] D. Wu, S. Cai, and G. Huang, "Coupled effect of cement hydration and temperature on rheological properties of fresh cemented tailings backfill slurry," Transactions of Nonferrous Metals Society of China, vol. 24, no. 9, pp. 2954-2963, 2014.

[20] J. H. Kim, S. H. Kwon, S. Kawashima, and H. Jae Yim, "Coupled effect of cement hydration and temperature on rheological properties of fresh cemented tailings backfill slurry," Cement and Concrete Composites, vol. 77, pp. 60-67, 2017.
[21] J. H. Kim, S. H. Kwon, S. Kawashima, and H. J. Yim, "Rheology of cement paste under high pressure," Cement and Concrete Composites, vol. 77, pp. 60-67, 2017.

[22] D. A. Williams, A. W. Saak, and H. M. Jennings, "The influence of mixing on the rheology of fresh cement paste," Cement and Concrete Research, vol. 29, no. 9, pp. 1491-1496, 1999.

[23] C. F. Ferrarisa, K. H. Oblab, and R. Hill, "The influence of mineral admixtures on the rheology of cement paste and concrete," Cement and Concrete Research, vol. 31, no. 2, pp. 245-255, 2001.

[24] N. Mikanovic and C. Jolicoeur, "Influence of superplasticizers on the rheology and stability of limestone and cement pastes," Cement and Concrete Research, vol. 38, no. 7, pp. 907-919, 2008.

[25] C. Brumaud, R. Baumannb, M. Schmitz, M. Radler, and N. Roussel, "Cellulose ethers and yield stress of cement pastes," Cement and Concrete Research, vol. 55, pp. 29542963, 2014.

[26] H. Bessaies-Bey, R. Baumann, M. Schmitz, M. Radler, and N. Roussel, "Effect of polyacrylamide on rheology of fresh cement pastes," Cement and Concrete Research, vol. 76, pp. 98-106, 2015.

[27] P. Ghoddousi, A. A. S. Javid, and J. Sobhani, "Effects of particle packing density on the stability and rheology of selfconsolidating concrete containing mineral admixtures," Construction and Building Materials, vol. 53, pp. 102-109, 2014.

[28] I. P. Sfikas, E. G. Badogiannis, and K. G. Trezos, "Rheology and mechanical characteristics of self-compacting concrete mixtures containing metakaolin," Construction and Building Materials, vol. 64, pp. 121-129, 2014.

[29] Y. Zhang, X. Luo, X. Kong, F. Wang, and L. Gao, "Rheological properties and microstructure of fresh cement pastes with varied dispersion media and superplasticizers," Powder Technology, vol. 330, pp. 219-227, 2018.

[30] J. Hot, H. Bessaies-Bey, C. Brumaud, M. Duc, C. Castella, and N. Roussel, "Adsorbing polymers and viscosity of cement pastes," Cement and Concrete Research, vol. 63, pp. 12-19, 2014.

[31] H. Bessaies-Bey, R. Baumann, M. Schmitz, M. Radler, and N. Roussel, "Organic admixtures and cement particles: competitive adsorption and its macroscopic rheological consequences," Cement and Concrete Research, vol. 80, pp. 1-9, 2016.

[32] M.-H. Zhang, K. Sisomphon, T. S. Ng, and D. J. Sun, "Effect of superplasticizers on workability retention and initial setting time of cement pastes," Construction and Building Materials, vol. 24, no. 9, pp. 1700-1707, 2010.

[33] C. A. Anagnostopoulos, "Effect of different superplasticisers on the physical and mechanical properties of cement grouts," Construction and Building Materials, vol. 50, pp. 162-168, 2014.

[34] N. A. Tregger, M. E. Pakula, and S. P. Shah, "Influence of clays on the rheology of cement pastes," Cement and Concrete Research, vol. 40, no. 3, pp. 384-391, 2010.

[35] L. Senffa, D. Hotzab, S. Lucasc, V. M. Ferreirac, and J. A. Labrinchaa, "Effect of nano- $\mathrm{SiO}_{2}$ and nano- $\mathrm{TiO}_{2}$ addition on the rheological behavior and the hardened properties of cement mortars," Materials Science and Engineering A, vol. 532, pp. 354-361, 2012.

[36] M. Jalal, M. Fathi, and M. Farzad, "Effects of fly ash and $\mathrm{TiO}_{2}$ nanoparticles on rheological, mechanical, microstructural and 
thermal properties of high strength self-compacting concrete," Mechanics of Materials, vol. 61, pp. 11-27, 2013.

[37] P. Hou, S. Kawashima, K. Wangc, D. J. Corr, J. Qian, and S. P. Shah, "Effects of colloidal nanosilica on rheological and mechanical properties of fly ash-cement mortar," Cement and Concrete Composites, vol. 35, no. 1, pp. 12-22, 2013.

[38] Y. C. Flores, G. C. Cordeiro, R. D. T. Filho, and L. M. Tavares, "Performance of Portland cement pastes containing nanosilica and different types of silica," Construction and Building Materials, vol. 146, pp. 524-530, 2017.

[39] E. Garcia-Taengua, M. Sonebi, K. M. A. Hossain, M. Lachemi, and J. Khatib, "Effects of the addition of nanosilica on the rheology, hydration and development of the compressive strength of cement mortars," Composites Part B, vol. 81, pp. 120-129, 2015.

[40] Q. Wang, J. Wang, C. Lv, X. Cui, S. Li, and X. Wang, "Rheological behavior of fresh cement pastes with a graphene oxide additive," New Carbon Materials, vol. 31, no. 6, pp. 574-584, 2016.

[41] F. Collins, J. Lambert, and W. Hui Duan, "The influences of admixtures on the dispersion, workability, and strength of carbon nanotube-OPC paste mixtures," Cement and Concrete Composites, vol. 34, no. 2, pp. 201-207, 2012.

[42] O. A. M. Realesa, Y. P. A. Jaramillob, J. C. O. Boterob et al., "Influence of MWCNT/surfactant dispersions on the rheology of Portland cement pastes," Cement and Concrete Research, vol. 107, pp. 101-109, 2018.

[43] R. Nadiv, G. Vasilyev, M. Shtein et al., "The multiple roles of a dispersant in nanocomposite systems," Composites Science and Technology, vol. 133, pp. 192-199, 2016.

[44] B. Zou, S. J. Chen, A. H. Korayem et al., "Effect of ultrasonication energy on engineering properties of carbon nanotube reinforced cement pastes," Carbon, vol. 85, pp. 212-220, 2015.

[45] S. Ma, Y. Qian, and S. Kawashima, "Performance-based study on the rheological and hardened properties of blended cement mortars incorporating palygorskite clays and carbon nanotubes," Construction and Building Materials, vol. 171, pp. 663-671, 2018.

[46] A. Yahia, S. Mantellato, and R. J. Flatt, "Concrete rheology: a basis for understanding chemical admixtures," in Science and Technology of Concrete Admixtures, pp. 97-127, Woodhead Publishing, Cambridge, UK, 2016.

[47] B. Feneuil, O. Pitois, and N. Roussel, "Effect of surfactants on the yield stress of cement paste," Cement and Concrete Research, vol. 100, pp. 32-39, 2017.

[48] D. Marchon, P. Juilland, E. Gallucci, L. Frunz, and R. J. Flatt, "Molecular and submolecular scale effects of combcopolymers on tri-calcium silicate reactivity: toward molecular design," Journal American Ceramic Society, vol. 100, no. 3, pp. 817-841, 2017. 


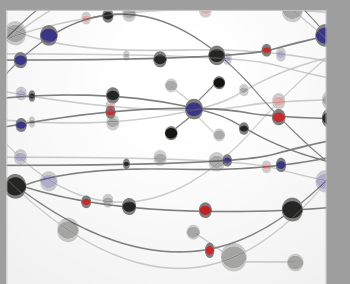

The Scientific World Journal
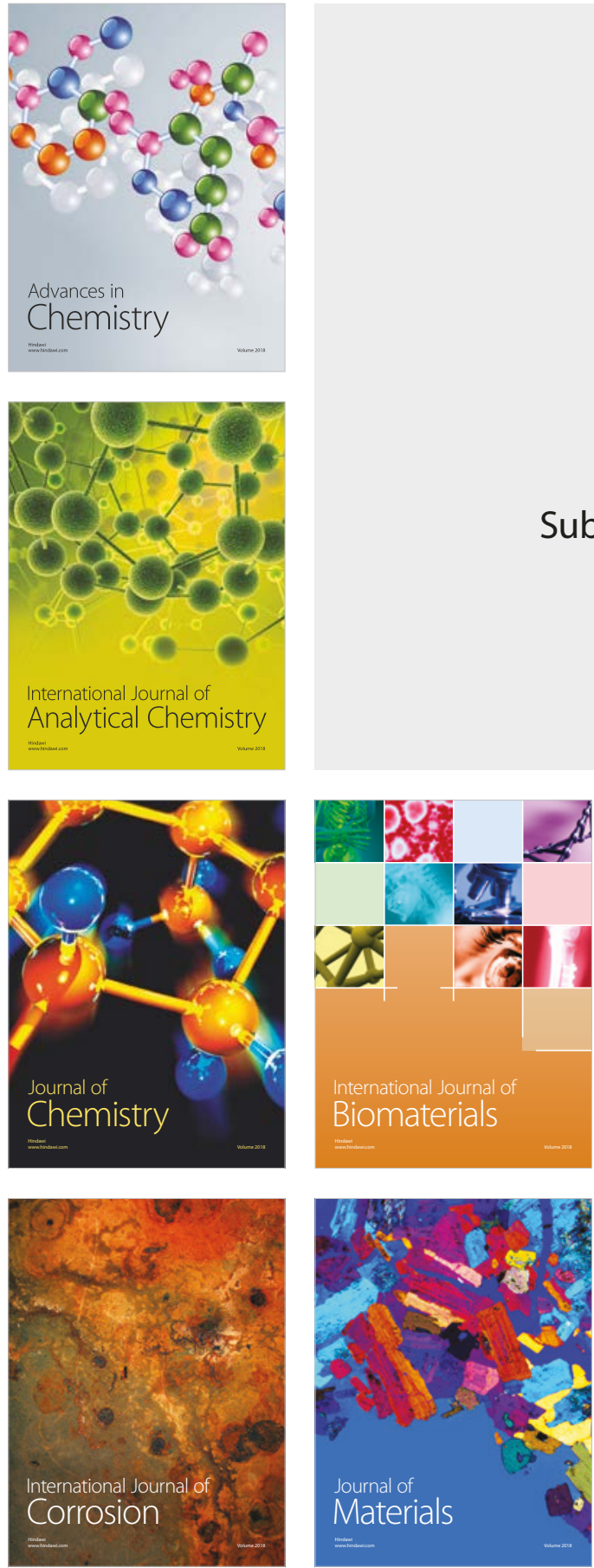

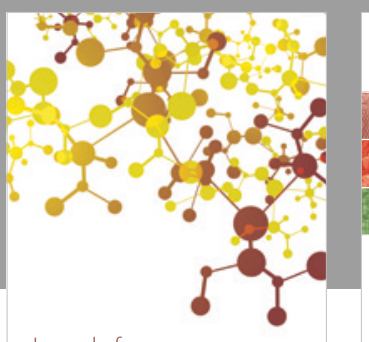

Journal of

Applied Chemistry
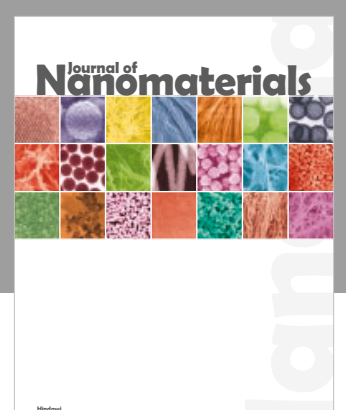

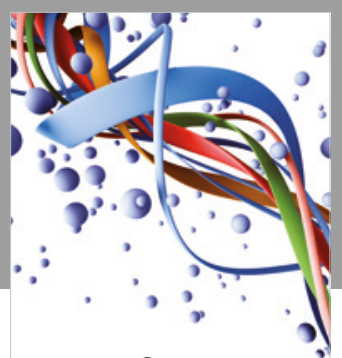

Scientifica

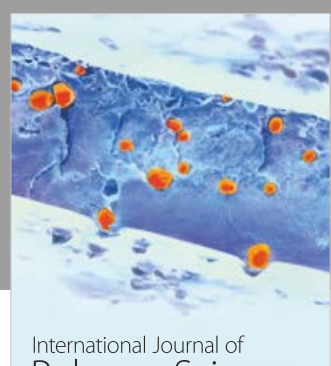

Polymer Science

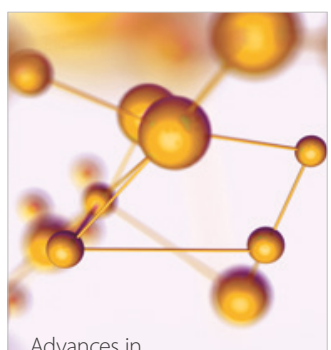

Physical Chemistry
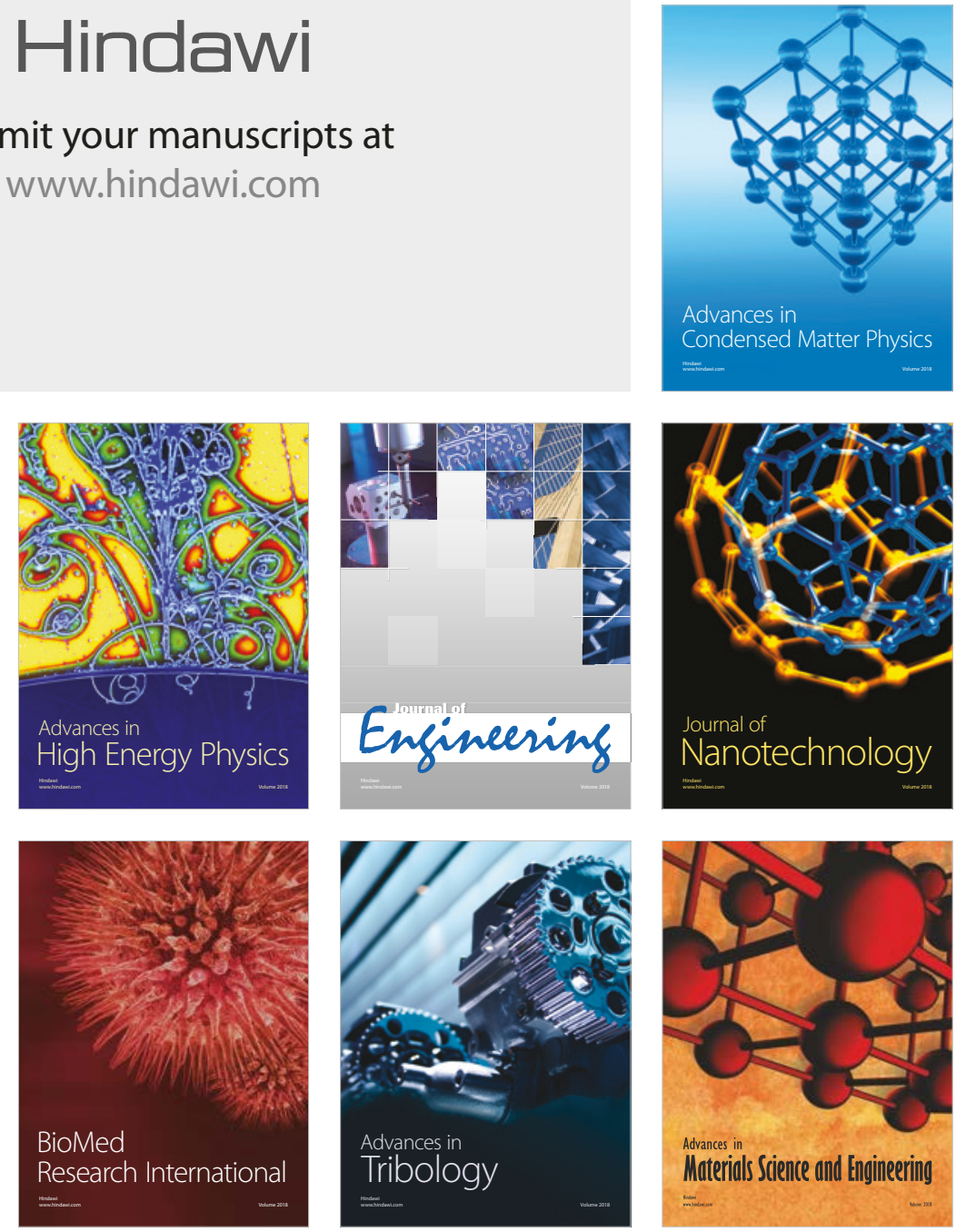